\title{
Influence of the Generator in-Growth Time on the Final Radiochemical Purity and Stability of ${ }^{99} \mathrm{~m}_{\text {Tc Radiopharmaceuticals }}$
}

\author{
L. Uccelli, ${ }^{1}$ A. Boschi, ${ }^{1}$ M. Pasquali, ${ }^{1}$ A. Duatti, ${ }^{1}$ G. Di Domenico, ${ }^{2}$ G. Pupillo, ${ }^{2}$ \\ J. Esposito, ${ }^{3}$ M. Giganti, ${ }^{1}$ A. Taibi, ${ }^{2}$ and M. Gambaccini ${ }^{2}$ \\ ${ }^{1}$ Dipartimento di Morfologia, Chirurgia e Medicina Sperimentale, Sezione di Diagnostica per Immagini, \\ Università di Ferrara and INFN, Sezione di Ferrara, Via Luigi Borsari 46, 44121 Ferrara, Italy \\ ${ }^{2}$ Dipartimento di Fisica e Scienze della Terra, Università di Ferrara and INFN, Sezione di Ferrara, Via Saragat 1, 44122 Ferrara, Italy \\ ${ }^{3}$ INFN, Laboratori Nazionali di Legnaro (LNL), Via dell'Università 2, 35020 Legnaro, Italy
}

Correspondence should be addressed to A. Boschi; alessandra.boschi@unife.it

Received 31 May 2013; Accepted 13 August 2013

Academic Editor: Mushtaq Ahmad

Copyright (C) 2013 L. Uccelli et al. This is an open access article distributed under the Creative Commons Attribution License, which permits unrestricted use, distribution, and reproduction in any medium, provided the original work is properly cited.

\begin{abstract}
At Legnaro laboratories of the Italian National Institute for Nuclear Physics (INFN), a feasibility study has started since 2011 related to accelerated-based direct production of ${ }^{99 \mathrm{~m}} \mathrm{Tc}$ by the ${ }^{100} \mathrm{Mo}(\mathrm{p}, 2 \mathrm{n}){ }^{99 \mathrm{~m}} \mathrm{Tc}$ reaction. Both theoretical investigations and some recent preliminary irradiation tests on ${ }^{100} \mathrm{Mo}$-enriched samples have pointed out that both the ${ }^{99 \mathrm{~g}} \mathrm{Tc} /{ }^{99 \mathrm{~m}} \mathrm{Tc}$ ratio and the ${ }^{99 \mathrm{~m}} \mathrm{Tc}$ specific activity will be basically different in the final accelerator-produced $\mathrm{Tc}$ with respect to generator-produced one, which might affect the radiopharmaceutical procedures. The aim of this work was to evaluate the possible impact of different ${ }^{99 \mathrm{~g}} \mathrm{Tc} /{ }^{99 \mathrm{~m}} \mathrm{Tc}$ isomeric ratios on the preparation of different Tc-labeled pharmaceutical kits. A set of measurements with ${ }^{99 \mathrm{~m}} \mathrm{Tc}$, eluted from a standard ${ }^{99} \mathrm{Mo} /{ }^{99 \mathrm{~m}} \mathrm{Tc}$ generator, was performed, and results on both radiochemical purity and stability studies (following the standard quality control procedures) are reported for a set of widely used pharmaceuticals (i.e., ${ }^{99 \mathrm{~m}}$ Tc-Sestamibi, ${ }^{99 \mathrm{~m}} \mathrm{Tc}-\mathrm{ECD}$, ${ }^{99 \mathrm{~m}}$ Tc-MAG3, ${ }^{99 \mathrm{~m}}$ Tc-DTPA, ${ }^{99 \mathrm{~m}}$ Tc-MDP, ${ }^{99 \mathrm{~m}} \mathrm{Tc}-\mathrm{HMDP},{ }^{99 \mathrm{~m}} \mathrm{Tc}$-nanocolloids, and $\left.{ }^{99 \mathrm{~m}} \mathrm{Tc}-\mathrm{DMSA}\right)$. These pharmaceuticals have been all reconstituted with either the first $\left[{ }^{99} \mathrm{TcO}_{4}\right]^{-}$eluate obtained from a ${ }^{99} \mathrm{Mo} /{ }^{99 \mathrm{~m}} \mathrm{Tc}$ generator (coming from two different companies) or eluates after $24,36,48$, and 72 hours from last elution. Results show that the radiochemical purity and stability of these radiopharmaceuticals were not affected up to the value of 11.84 for the ${ }^{99 \mathrm{~g}} \mathrm{Tc} /{ }^{99 \mathrm{~m}} \mathrm{Tc}$ ratio.
\end{abstract}

\section{Introduction}

${ }^{99} \mathrm{~m}$ Tc, with its peculiar physical-chemical properties, still continues to be the most important radionuclide used in diagnostic nuclear medical procedures. In particular, the developments of technetium chemistry have opened new perspectives in the field of diagnostic imaging [1]. More than $80 \%$ of the radiopharmaceuticals are currently labeled with this radionuclide [1] by reconstitution with sodium pertechnetate [2-4] $\left[\mathrm{Na}^{99 \mathrm{~m}} \mathrm{TcO}_{4}\right]$ commercial kits containing in lyophilized form the various reagents required for the preparation of each radiopharmaceutical. Its routine applications are ensured by the availability of portable ${ }^{99} \mathrm{Mo} /{ }^{99 m} \mathrm{Tc}$ generators in which ${ }^{99} \mathrm{Mo}$ is bound as molybdate anion to alumina columns. Current global interruptions of ${ }^{99} \mathrm{Mo}$ supply that involved uranium fission of highly enriched ${ }^{235} \mathrm{U}$ targets, aging reactors, and the staggering costs of their maintenance, focused on the search for alternative method of the ${ }^{99 \mathrm{~m}} \mathrm{Tc}$ production [5]. One of the possibilities is to replace the reactors with particle accelerators, aiming at a regional production and distribution. At Legnaro laboratories of the Italian National Institute for Nuclear Physics (INFN), a feasibility study related to accelerated-based direct production of ${ }^{99 \mathrm{~m}} \mathrm{Tc}$ by the ${ }^{100} \mathrm{Mo}(\mathrm{p}, 2 \mathrm{n}){ }^{99 \mathrm{~m}} \mathrm{Tc}$ reaction $[6,7]$ has started since 2011. Theoretical investigations and some recent preliminary irradiation tests on ${ }^{100} \mathrm{Mo}$-enriched samples point out that both the ${ }^{99 \mathrm{~g}} \mathrm{Tc} /{ }^{99 \mathrm{~m}} \mathrm{Tc}$ ratio and ${ }^{99 \mathrm{~m}} \mathrm{Tc}$ specific 
TABLE 1: Radiopharmaceuticals used in the study.

\begin{tabular}{|c|c|}
\hline Name & Radiopharmaceutical \\
\hline Neurolite (Brystol-Myer Squibb) & ${ }^{99 \mathrm{~m}} \mathrm{Tc}-\mathrm{ECD}\left({ }^{99 \mathrm{~m}} \mathrm{Tc}-\right.$ Bicisato $)$ \\
\hline Cardiolite (Brystol-Myer Squibb) & ${ }^{99 \mathrm{~m}}$ Tc-SESTAMIBI \\
\hline Stamicis (IBA) & ${ }^{99 \mathrm{~m}}$ Tc-SESTAMIBI \\
\hline Technemibi (Mallinckrodt) & ${ }^{99 \mathrm{~m}}$ Tc-SESTAMIBI \\
\hline TechneScan (Mallinckrodt) & ${ }^{99 \mathrm{~m}} \mathrm{Tc}-\mathrm{MAG} 3$ \\
\hline Pentacis (IBA) & ${ }^{99 \mathrm{~m}}$ Tc-DTPA \\
\hline $\begin{array}{l}\text { Medronato II (GE Healthcare) } \\
\text { Osteocis (IBA) }\end{array}$ & $\begin{array}{l}{ }^{99 m} \mathrm{Tc}-\mathrm{MDP} \\
{ }^{99 \mathrm{~m}} \mathrm{Tc}-\mathrm{HMDP}\end{array}$ \\
\hline Nanocoll (GE Healthcare) & ${ }^{99 \mathrm{~m}} \mathrm{Tc}$-nanocolloids \\
\hline Renocis (IBA) & ${ }^{99 \mathrm{~m}}$ Tc-DMSA \\
\hline
\end{tabular}

activity will be basically different in the final acceleratorproduced Tc with respect to generator-produced one, due to the concomitant production of Tc contaminant nuclides, such as ${ }^{99 \mathrm{~g}} \mathrm{Tc},{ }^{98} \mathrm{Tc},{ }^{97 \mathrm{~m}} \mathrm{Tc}$, and ${ }^{97 \mathrm{~g}} \mathrm{Tc}$. In particular, the amount of the ground-state long-lived $\beta^{-}$emitter ${ }^{99 \mathrm{~g}} \mathrm{Tc}$, useless for diagnostic procedures, might have a negative effect in the radiopharmaceutical procedures going to compete with ${ }^{99} \mathrm{~m}$ Tc for the formation of the corresponding chemically identical radiopharmaceuticals. The presence of an excess of ${ }^{99 \mathrm{~g}} \mathrm{Tc}$ might be responsible for a value of radiochemical purity lower than the standard required for some radiopharmaceutical preparations. In fact, the ${ }^{99 \mathrm{~g}} \mathrm{Tc}$ present in solution could consume reagents of reaction, and in particular the reducing agent $\left(\mathrm{SnCl}_{2}\right)$. As a result, unreacted $\left[{ }^{99 \mathrm{~m}} \mathrm{TcO}_{4}\right]^{-}$ may remain in the solution, or radioactive by-products not useful for the specific diagnostic procedure may be formed. The quality of ${ }^{99 \mathrm{~m}} \mathrm{Tc}$ is then fundamental for the assurance of radiopharmaceuticals quality [8-10]. The aim of this work was therefore to perform a set of measurements with ${ }^{99 \mathrm{~m}} \mathrm{Tc}$, eluted from a standard ${ }^{99} \mathrm{Mo} /{ }^{99 \mathrm{~m}} \mathrm{Tc}$ generator, in order to first check possible impact of different ${ }^{99 \mathrm{~g}} \mathrm{Tc} /{ }^{99 \mathrm{~m}} \mathrm{Tc}$ isomeric ratios on the preparation of different Tc-labeled pharmaceutical kits. Results on both radiochemical purity and stability studies (following the standard quality control procedures) are reported for a set of widely used pharmaceuticals (i.e., ${ }^{99 \mathrm{~m}} \mathrm{Tc}$ Sestamibi, ${ }^{99 \mathrm{~m}}$ Tc-ECD, ${ }^{99 \mathrm{~m}}$ Tc-MAG3, ${ }^{99 \mathrm{~m}}$ Tc-DTPA, ${ }^{99 \mathrm{~m}} \mathrm{Tc}-$ MDP, ${ }^{99 \mathrm{~m}}$ Tc-HMDP, ${ }^{99 \mathrm{~m}}$ Tc-nanocolloids, and ${ }^{99 \mathrm{~m}} \mathrm{Tc}$-DMSA). These pharmaceuticals have been all reconstituted with either the first $\left[{ }^{99 \mathrm{~m}} \mathrm{TcO}_{4}\right]^{-}$eluate obtained from the ${ }^{99} \mathrm{Mo} /{ }^{99 m} \mathrm{Tc}$ generator (coming from two different companies) or eluates after 24, 36, 48, and 72 hours from last elution.

\section{Materials and Methods}

The preparation of radiopharmaceuticals reported in Table 1 was carried out with sodium pertechnetate eluates coming from two different ${ }^{99} \mathrm{Mo} /{ }^{99 \mathrm{~m}}$ Tc generators: a "dry" DRYTEC generator (GE Healthcare, Via Galeno 36 20126, Milan), and a "wet" Elumatic III generator (IBA-CIS Bio International, Route Nationale 306, Saclay BP 32, 91192 GIF SUR YVETTE, Cedex France).
All generators, with ${ }^{99}$ Mo calibrated activity of $10 \mathrm{GBq}$, were eluted with $5 \mathrm{~mL}$ of saline solution as indicated by each manufacturer. From each generator, we analyzed and compared the three first elutions, performed just after generator delivery (time elapsed between manufacturing and first use can be estimate in 2-3 days), and 3 elutions were carried out after 36,48 , and 72 hours from the previous elution.

2.1. Quality Control of ${ }^{99} \mathrm{Mo} /{ }^{99 m} \mathrm{Tc}$ Generator Eluates. Generator eluates have been subjected to all the tests [11] required by European Pharmacopoeia [14], and Italian Pharmacopoeia, 12th edn., Norme di Buona Preparazione dei Radiofarmaci per Medicina Nucleare, All. A, p.to A.2 "Generatore di ${ }^{99} \mathrm{Mo} /{ }^{99 \mathrm{~m}} \mathrm{Tc}$ (molibdeno/tecnezio)".

2.1.1. Generator Elution Yield. It was expressed as \% of the ratio between the eluate radioactivity measured immediately after elution using a dose calibrator $\left(V_{M}\right)$ and the theoretical radioactivity $\left(V_{C}\right)$ calculated on the basis of the date of calibration and multiplied by the factor 100 [3]. The elution efficiency should be within the range of $90 \%-110 \%$.

2.1.2. Eluate Visual Inspection. All eluates were visually inspected, pulling the vial from its shielded container. The operation was performed within an adequately shielded cell for radiopharmaceuticals manipulation; the vial containing the pertechnetate eluate was manipulated by operators using a pair of pliers to guarantee an adequate distance from the hands of the operator.

2.1.3. Eluate $p H$. Generator eluate is itself a preparation for injection; ideally it should have a $\mathrm{pH}$ as close as possible to the physiological, between 7 and 8. The Pharmacopeia requires that eluates have $\mathrm{pH}$ values within the range of $4-8$. Since the molybdenum is adsorbed onto the alumina in an acid environment, the $\mathrm{pH}$ values of eluates are slightly acid (4.56). It was measured by means of $\mathrm{pH}$ usual indicator strip (range $0-14$ ) and checked by electronic $\mathrm{pH}$-meter.

2.1.4. Aluminum Content. It was determined by a semiquantitative procedure employing indicator strips (Tec-Control Biodex Medical, New York, USA) together with standard aluminium solution $[12,13]$. A drop of standard solution with a concentration less than $5 \mu \mathrm{g} \mathrm{mL} \mathrm{m}^{-1}$ of aurintricarboxylic acid was deposited on indicator paper; subsequently, by side a drop of eluate was deposited. If the coloration produced by the latter is lower than the one produced by the standard solution, it can be assumed that the concentration of aluminium in the eluate is less than the maximum acceptable level of $5 \mu \mathrm{g} \mathrm{mL}^{-1}$ provided by Official Pharmacopoeia [14].

2.1.5. Radionuclidic Purity. Radionuclidic purity is the percentage of total radioactivity which may be attributed to the daughter radionuclide. In the case of fission-produced generator, the largest potential source of contamination that could exceed the minimum value detectable can be due to the parent $\left({ }^{99} \mathrm{Mo}\right)$ [15]. Trace amount of other fission impurities $[16,17]$ may be usually present in negligible amounts. 


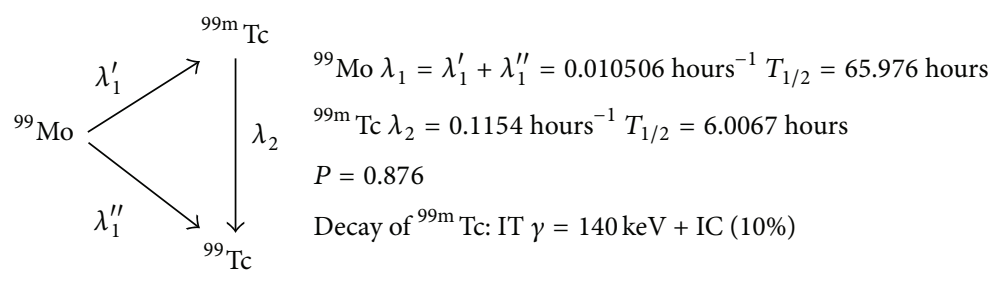

FIgURE 1: Simplified decay scheme of ${ }^{99}$ Mo to ${ }^{99} \mathrm{Tc}$.

The early and quick evaluation of the eluate content of ${ }^{99} \mathrm{Mo}$ was provided by the following procedure, which involved the use of a lead shield of appropriate thickness $\left(0.6 \mathrm{~mm}\right.$ of lead) in order to attenuate ${ }^{99 \mathrm{~m}} \mathrm{Tc}$ emission [18]. The activity contained in the unshielded elution vial was measured with a dose calibrator (PET-dose, Comecer, Castelbolognese, Italy); for measuring ${ }^{99} \mathrm{Mo}$ activity, the elution vial was then placed within the lead shield and its activity was recorded. The thickness of the shield was enough to largely attenuate the $140 \mathrm{keV}$ photons [19], and only partly those greater than $700 \mathrm{keV}$. The measured activity, multiplied by a suitable correction factor which accounts for the attenuation of $740-780 \mathrm{keV}$ photons due to the lead shielding, provides an estimation of the ${ }^{99} \mathrm{Mo}$ activity. This value should not exceed $0.1 \%$ of the ${ }^{99 \mathrm{~m}} \mathrm{Tc}$ activity according to the European Pharmacopoeia.

For a more accurate determination of the radionuclidic purity $[17,20]$, the same eluate sample was examined again (reassayed) after 7-15 days by means of high-resolution gamma spectrometry using a solid-state, high-purity germanium detector [16].

2.1.6. Radiochemical Purity. It was checked by paper chromatography, Whatman no.l paper strips and saline as mobile phase. According to this procedure, ${ }^{99 \mathrm{~m}} \mathrm{TcO}_{4}{ }^{-}$migrates with the solvent front $\left(R_{f}=1\right)$, whereas reduced hydrolyzed ${ }^{99 \mathrm{~m}} \mathrm{Tc}$ remains at the origin $\left(R_{f}=0\right)$. The radioactivity distribution was measured by a scanning radiochromatography detection system for thin layer chromatography (Cyclone instrument equipped with a phosphor imaging screen and an OptiQuant image analysis software (Packard, Meridien, CT)). Eluate radiochemical purity should be greater than $95 \%$.

2.1.7. ${ }^{99} \mathrm{~g}$ Tc to Active ${ }^{99 m}$ Tc Ratio. ${ }^{99}$ Mo decays to ${ }^{99 \mathrm{~g}} \mathrm{Tc}$ (12.4\%) and ${ }^{99 \mathrm{~m}} \mathrm{Tc}(87.6 \%)$, and the latter, with a physical $T_{1 / 2}$ of $6.0067 \mathrm{~h}$, decays to ${ }^{99 \mathrm{~g}} \mathrm{Tc}\left(T_{1 / 2}=211,100\right.$ years). Due to this particular branching decay of ${ }^{99} \mathrm{Mo}$, even fresh elutions from a generator always contain both isotopes $\left({ }^{99 \mathrm{~m}} \mathrm{Tc}\right.$ and ${ }^{99 \mathrm{~g}} \mathrm{Tc}$ ), indistinguishable from the chemical point of view. The amount $(\mu \mathrm{g})$ of total technetium present in the eluate is directly related to the amount of ${ }^{99} \mathrm{Mo}$ atoms present on the column (i.e., ${ }^{99}$ Mo activity) and the time that elapsed since the previous elution. The total number of Tc atoms, namely, the sum of ${ }^{99 \mathrm{~g}} \mathrm{Tc}$ and ${ }^{99 \mathrm{~m}} \mathrm{Tc}$, has been calculated as follows:

$$
N_{\mathrm{Tc}(\text { total })}=N_{99}^{\circ} \mathrm{Mo}\left(1-e^{-\lambda_{1} t}\right),
$$

where $N_{99}^{\circ}$ io is the initial ${ }^{99} \mathrm{Mo}$ atoms number present on the column, $\lambda_{1}$ is the decay constant of ${ }^{99} \mathrm{Mo}\left(0.0105\right.$ hours $\left.^{-1}\right)$, and $t$ is the time that elapsed since the last elution. The number of ${ }^{99 \mathrm{~m}} \mathrm{Tc}$ atoms has been calculate as follows:

$$
N_{99 \mathrm{~m} T \mathrm{Tc}}=P \frac{\lambda_{1}}{\lambda_{2}-\lambda_{1}} N_{99 \mathrm{Mo}}^{\circ}\left(e^{-\lambda_{1} t}-e^{-\lambda_{2} t}\right),
$$

where $\lambda_{2}$ is the decay constant of ${ }^{99 \mathrm{~m}} \mathrm{Tc}\left(0.1149\right.$ hours $\left.^{-1}\right)$ and $P$ is the decay probability $(P=0.876)$. A simplified decay scheme of ${ }^{99} \mathrm{Mo}$ to ${ }^{99 \mathrm{~g}} \mathrm{Tc}$ is shown in Figure 1. From the above equations the number of ${ }^{99 \mathrm{~g}} \mathrm{Tc}$ atoms can be easily calculated as follows:

$$
N_{9_{\mathrm{g}} \mathrm{Tc}}=N_{\text {Total Tc }}-N_{99_{\mathrm{m}} \mathrm{Tc}}
$$

and thus the ${ }^{99 \mathrm{~g}} \mathrm{Tc}$ to active ${ }^{99 \mathrm{~m}} \mathrm{Tc}$ ratio can be estimated.

The determination of the ${ }^{99 \mathrm{~g}} \mathrm{Tc}$ content in a fresh eluate requires an immediate measurement after the elution of the ${ }^{99 \mathrm{~m}} \mathrm{Tc}$ activity and a later measurement of the total activity of ${ }^{99 \mathrm{~g}} \mathrm{Tc}$ (in a few months almost all the ${ }^{99} \mathrm{Mo}$ and ${ }^{99 \mathrm{~m}} \mathrm{Tc}$ atoms decay into ${ }^{99 \mathrm{~g}} \mathrm{Tc}$ ). The evaluation of ${ }^{99 \mathrm{~m}} \mathrm{Tc}$ activity in the sample has been performed by using a dose calibrator (PET-dose, Comecer, Castelbolognese, Italy), while the evaluation of ${ }^{99 \mathrm{~g}} \mathrm{Tc}$ activity has been performed using the TRI-CARB 2810TR liquid scintillation analyzer (Perkin Elmer Inc., Monza, Italy). The samples for ${ }^{99} \mathrm{Tc}$ activity measurements were prepared taking an aliquot of $0.8 \mathrm{~mL}$ from an eluate decayed for 60 days (total volume of the eluate: $5 \mathrm{~mL}$ ) and adding $5.4 \mathrm{~mL}$ of liquid scintillator (Ultima Gold LLT cocktail, Perkin Elmer Inc., Monza, Italy). The measurement of ${ }^{99 \mathrm{~g}} \mathrm{Tc}$ activity was performed using the 0 $295 \mathrm{keV}$ energy window.

2.2. Radiopharmaceuticals Labeling. The elutions were used to label different commercial kits (Table 1). Kits reconstitution was performed according to the methods described in the package included within the commercial kits. The radiochemical purity $(\mathrm{RCP})$ of radiopharmaceuticals was evaluated immediately after preparation $(t=0)$ and at the end of the stability period indicated by the manufacturer. The radiochemical purity and stability were measured using methods specified by manufacturer, with the exception of TechneScan (Mallinckrodt) for which the following chromatographic system was used [21]: mobile phase, 54/45/1 (physiological/methanol/glacial acetic acid) and stationary phase, RP-18 (Merck). Thin-layer chromatography plates were analyzed with a Cyclone instrument equipped with a 
TABLe 2: $\mathrm{pH},{ }^{99} \mathrm{Mo},{ }^{103} \mathrm{Ru}$, and ${ }^{131} \mathrm{I}$ amounts and radiochemical purities (mean \pm standard deviation) of the evaluated generators' elutions.

\begin{tabular}{|c|c|c|c|c|c|c|}
\hline Type of generator & Type of elution & $\mathrm{pH}$ & ${ }^{99} \mathrm{Mo} \%$ & ${ }^{103} \mathrm{Ru} \%$ & ${ }^{131} \mathrm{I} \%$ & RCP \% \\
\hline \multirow{4}{*}{ Drytec-GE } & $1^{\circ}$ eluate & $6.0 \pm 0.3$ & $(2.1 \pm 0.2) \times 10^{-2}$ & $(1.9 \pm 0.2) \times 10^{-6}$ & $(1.4 \pm 0.4) \times 10^{-7}$ & $99.8 \pm 0.3$ \\
\hline & $36 \mathrm{~h}$ & $6.0 \pm 0.4$ & $(3.9 \pm 0.5) \times 10^{-2}$ & - & & $99.7 \pm 0.3$ \\
\hline & $48 \mathrm{~h}$ & $6.1 \pm 0.3$ & $(3.7 \pm 0.4) \times 10^{-2}$ & - & & $99.8 \pm 0.2$ \\
\hline & $72 \mathrm{~h}$ & $6.0 \pm 0.2$ & $(3.1 \pm 0.2) \times 10^{-2}$ & - & & $99.7 \pm 0.3$ \\
\hline \multirow{4}{*}{ Elumatic III } & $1^{\circ}$ eluate & $6.2 \pm 0.1$ & $(2.7 \pm 0.3) \times 10^{-2}$ & $(1.7 \pm 0.5) \times 10^{-7}$ & $(2.2 \pm 0.3) \times 10^{-7}$ & $99.8 \pm 0.1$ \\
\hline & $36 \mathrm{~h}$ & $6.2 \pm 0.3$ & $(2.5 \pm 0.5) \times 10^{-2}$ & - & & $99.8 \pm 0.3$ \\
\hline & $48 \mathrm{~h}$ & $6.2 \pm 0.4$ & $(2.5 \pm 0.1) \times 10^{-2}$ & - & & $99.6 \pm 0.2$ \\
\hline & $72 \mathrm{~h}$ & $6.1 \pm 0.2$ & $(2.5 \pm 0.3) \times 10^{-2}$ & - & & $99.4 \pm 0.1$ \\
\hline E.P. & & $4.8-8.0$ & $<0.1 \%$ & $<5 \times 10^{-3}$ & $<5 \times 10^{-3}$ & $\geq 95.0$ \\
\hline
\end{tabular}

E.P.: European pharmacopoeia; 36,48 , and $72 \mathrm{~h}$ indicate the time from the previous elution; the amount of ${ }^{99}$ Mo represents the \% of total radioactivity in the generators' eluates determined with "rapid method"; ${ }^{103} \mathrm{Ru}(0.497 \mathrm{MeV})$ and ${ }^{131} \mathrm{I}(0.365 \mathrm{MeV})$ are the most common gamma radionuclide detectable by gamma spectrometry, and in the table are reported the $\%$ of total radioactivity in the generators' eluates.

TABLE 3: RCP of radiopharmaceuticals at $t=0$, prepared with generator DRYTEC GE Healthcare eluates at time superior to $24 \mathrm{~h}$ from the last elution.

\begin{tabular}{|c|c|c|c|c|c|}
\hline Commercial name & Radiopharmaceuticals & $\mathrm{RCP}_{36}$ & $\mathrm{RCP}_{48}$ & $\mathrm{RCP}_{72}$ & RCP requirements \\
\hline Neurolite & ${ }^{99 \mathrm{~m}} \mathrm{Tc}-\mathrm{ECD}$ & $98.57 \pm 0.45$ & $99.41 \pm 1.51$ & $98.73 \pm 1.85$ & $\geq 90 \%$ \\
\hline Cardiolite & ${ }^{99 \mathrm{~m}} \mathrm{Tc}-$ Sestamibi & $97.91 \pm 0.38$ & $98.35 \pm 1.02$ & $99.40 \pm 1.23$ & $\geq 94 \%$ \\
\hline Stamicis & ${ }^{99 \mathrm{~m}}$ Tc-Sestamibi & $97.88 \pm 0.28$ & $97.90 \pm 0.15$ & $98.16 \pm 0.11$ & $\geq 94 \%$ \\
\hline Technemibi & ${ }^{99 \mathrm{~m}} \mathrm{Tc}-$ Sestamibi & $98.18 \pm 0.23$ & $97.77 \pm 0.33$ & $98.53 \pm 0.27$ & $\geq 94 \%$ \\
\hline TechneScan & ${ }^{99 \mathrm{~m}}$ Tc-MAG3 & $98.89 \pm 0.64$ & $99.10 \pm 0.44$ & $99.31 \pm 0.14$ & $\geq 95 \%$ \\
\hline Pentacis & ${ }^{99 \mathrm{~m}} \mathrm{Tc}-\mathrm{DTPA}$ & $98.84 \pm 1.01$ & $98.91 \pm 0.24$ & $99.12 \pm 0.33$ & $\geq 95 \%$ \\
\hline Medronato II & ${ }^{99 \mathrm{~m}} \mathrm{Tc}-\mathrm{MDP}$ & $99.01 \pm 0.24$ & $98.44 \pm 0.16$ & $99.63 \pm 0.64$ & $\geq 95 \%$ \\
\hline Osteocis & ${ }^{99 \mathrm{~m}}$ Tc-HMDP & $99.22 \pm 0.14$ & $98.01 \pm 0.52$ & $99.13 \pm 0.11$ & $\geq 95 \%$ \\
\hline Nanocoll $(\mathrm{PRC}=40 \mathrm{~min})$ & ${ }^{99 \mathrm{~m}} \mathrm{Tc}$-nanocolloids & $99.34 \pm 0.09$ & $99.38 \pm 0.16$ & $98.94 \pm 0.41$ & $\geq 95 \%$ \\
\hline Renocis & ${ }^{99 \mathrm{~m}}$ Tc-DMSA & $99.55 \pm 0.08$ & $99.22 \pm 0.77$ & $99.11 \pm 0.03$ & $\geq 95 \%$ \\
\hline
\end{tabular}

$\mathrm{RCP}_{36,48,72}$ indicate the radiochemical purity carried out with eluates obtained 36,48 and 72 hours after the previous elution.

phosphor imaging screen and an OptiQuant image analysis software (Packard, Meridien, CT).

2.3. Imaging Studies. Three ${ }^{99 \mathrm{~m}} \mathrm{Tc}$ eluates produced by ${ }^{99} \mathrm{Mo} /$ ${ }^{99 \mathrm{~m}} \mathrm{Tc}$ generator with different ${ }^{99 \mathrm{~g}} \mathrm{Tc} /{ }^{99 \mathrm{~m}} \mathrm{Tc}$ ratio $R$ were used for imaging studies; the $R$ values were 4.16, 9.51, and 15.2, respectively. Each tomographic acquisition has been performed by filling a NEMA phantom NU 4-2008 with $74 \mathrm{MBq}$ of ${ }^{99 \mathrm{~m}} \mathrm{Tc}$-pertechnetate solution, and the data have been acquired with the YAP-(S)PET small animal scanner prototype [22] and reconstructed by using an EM-ML algorithm.

\section{Results and Discussion}

The results of the quality control (Table 2) performed on all eluates obtained from two different generator (DRYTEC GE Healthcare and Elumatic III IBA) are consistent with the European Pharmacopoeia requirements [12]. For simplicity, data of visual inspection, yield of elution, and the aluminum content in eluates are not reported, because they fell within European Pharmacopoeia requirements.
The radiochemical purity (RCP) values of all radiopharmaceuticals labeled with each eluate are reported in Tables 3 and 4. Results refer to the RCP evaluated immediately after the preparation $(t=0)$. For simplicity, data at the end of the stability period specified by the manufacturer are not reported, because they fell within the specifications required by the manufacturer. Tables 5 and 6 report the RCP data obtained from reconstitution of the kits with the first eluate. The values refer to the checks carried out immediately after the preparation $(t=0)$ and at the end of the stability period specified by the manufacturer in the package insert of each radiopharmaceutical. The values of radiochemical purity are always superior to the standards required by the manufacturer. The results show that the total amount of technetium $\left({ }^{99 \mathrm{~g}} \mathrm{Tc}+{ }^{99 \mathrm{~m}} \mathrm{Tc}\right)$ present in the first eluate and in the eluates obtained at longer intervals, from $24 \mathrm{~h}$ up to $72 \mathrm{~h}$, did not affect the radiochemical purity of the final products. Table 7 shows an estimation of the total amount of technetium present in an eluate obtained from a ${ }^{99} \mathrm{~m}$ Tc generator with ${ }^{99} \mathrm{Mo}$ calibrated activity of $10 \mathrm{GBq}$. The ratios $R$ of three ${ }^{99 \mathrm{~m}}$ Tc eluates at 24 hours and two ${ }^{99 \mathrm{~m}}$ Tc first eluates at 48 hours have been measured, and the results have been $R_{24 \mathrm{~h}}=3.23 \pm 0.15$ and $R_{48 \mathrm{~h}}=6.68 \pm 0.31$, respectively. While 
TABLE 4: RCP of radiopharmaceuticals at $t=0$, prepared with generator Elumatic III (IBA) eluates at time superior to $24 \mathrm{~h}$ from the last elution.

\begin{tabular}{|c|c|c|c|c|c|}
\hline Commercial name & Radiopharmaceutical & $\mathrm{RCP}_{36}$ & $\mathrm{RCP}_{48}$ & $\mathrm{RCP}_{72}$ & RCP requirements \\
\hline Neurolite & ${ }^{99 \mathrm{~m}} \mathrm{Tc}-\mathrm{ECD}$ & $98.77 \pm 0.89$ & $99.21 \pm 0.71$ & $98.68 \pm 0.95$ & $\geq 90 \%$ \\
\hline Cardiolite & ${ }^{99 \mathrm{~m}}$ Tc-Sestamibi & $97.88 \pm 0.78$ & $98.83 \pm 0.92$ & $99.13 \pm 0.63$ & $\geq 94 \%$ \\
\hline Stamicis & ${ }^{99 \mathrm{~m}}$ Tc-Sestamibi & $98.78 \pm 0.23$ & $98.90 \pm 0.20$ & $98.00 \pm 0.19$ & $\geq 94 \%$ \\
\hline Technemibi & ${ }^{99 \mathrm{~m}}$ Tc-Sestamibi & $98.45 \pm 0.09$ & $98.17 \pm 0.23$ & $98.11 \pm 0.06$ & $\geq 94 \%$ \\
\hline TechneScan & ${ }^{99 \mathrm{~m}} \mathrm{Tc}-\mathrm{MAG} 3$ & $99.79 \pm 0.64$ & $98.10 \pm 0.44$ & $99.44 \pm 0.14$ & $\geq 95 \%$ \\
\hline Pentacis & ${ }^{99 \mathrm{~m}} \mathrm{Tc}-\mathrm{DTPA}$ & $99.14 \pm 0.12$ & $98.88 \pm 0.15$ & $98.12 \pm 1.03$ & $\geq 95 \%$ \\
\hline Medronato II & ${ }^{99 \mathrm{~m}} \mathrm{Tc}-\mathrm{MDP}$ & $99.11 \pm 0.33$ & $99.44 \pm 0.15$ & $99.11 \pm 0.43$ & $\geq 95 \%$ \\
\hline Osteocis & ${ }^{99 \mathrm{~m}} \mathrm{Tc}-\mathrm{HMDP}$ & $99.01 \pm 0.24$ & $98.44 \pm 0.16$ & $99.63 \pm 0.64$ & $\geq 95 \%$ \\
\hline Nanocoll $(P R C=40 \mathrm{~min})$ & ${ }^{99 \mathrm{~m}}$ Tc-nanocolloids & $98.99 \pm 0.03$ & $99.18 \pm 0.49$ & $98.11 \pm 0.11$ & $\geq 95 \%$ \\
\hline Renocis & ${ }^{99} \mathrm{~m}_{\mathrm{Tc}}-\mathrm{DMSA}$ & $99.35 \pm 0.22$ & $98.67 \pm 0.17$ & $99.03 \pm 0.29$ & $\geq 95 \%$ \\
\hline
\end{tabular}

$\mathrm{RCP}_{36,48,72}$ indicate the radiochemical purity carried out with eluates obtained 36,48 and 72 hours after the previous elution.

TABLE 5: RCP of radiopharmaceuticals at $t=0$ and at the expired time specified by the manufacturer, prepared with the first eluate obtained from DRYTEC GE Healthcare generator.

\begin{tabular}{lcccc}
\hline Commercial name & Radiopharmaceutical & RCP $(t=0)$ & RCPex & RCP requirements \\
\hline Neurolite & ${ }^{99 m}$ Tc-ECD & $99.17 \pm 0.25$ & $99.13 \pm 0.21$ & $\geq 90 \%$ \\
Cardiolite & ${ }^{99 m}$ Tc-Sestamibi & $97.67 \pm 1.24$ & $97.71 \pm 1.13$ & $\geq 94 \%$ \\
Stamicis & ${ }^{99 m}$ Tc-Sestamibi & $98.65 \pm 0.40$ & $98.57 \pm 0.57$ & $\geq 94 \%$ \\
Technemibi & ${ }^{99 m}$ Tc-Sestamibi & $98.15 \pm 0.11$ & $98.01 \pm 0.04$ & $\geq 94 \%$ \\
TechneScan & ${ }^{99 m}$ Tc-MAG3 & $98.79 \pm 0.02$ & $98.11 \pm 0.15$ & $\geq 95 \%$ \\
Pentacis & ${ }^{99}$ Tc-DTPA & $99.03 \pm 0.24$ & $99.88 \pm 0.11$ & $\geq 95 \%$ \\
Medronato II & ${ }^{99 m}$ Tc-MDP & $98.10 \pm 0.13$ & $98.02 \pm 0.15$ & $\geq 95 \%$ \\
Osteocis & ${ }^{99 m}$ Tc-HMDP & $99.23 \pm 0.18$ & $98.15 \pm 0.16$ & $\geq 95 \%$ \\
Nanocoll (PRC =40 min) & ${ }^{99 m}$ Tc-nanocolloids & $98.22 \pm 0.13$ & $98.33 \pm 0.39$ & $\geq 95 \%$ \\
Renocis & ${ }^{99 m}$ Tc-DMSA & $99.28 \pm 0.07$ & $98.55 \pm 0.21$ & \\
\hline
\end{tabular}

RCPex indicates the radiochemical purity at the end of the expired time.

TABLE 6: RCP of radiopharmaceuticals at $t=0$ and at the expired time specified by the manufacturer, prepared with the first eluate obtained from Elumatic III (IBA) generator.

\begin{tabular}{|c|c|c|c|c|}
\hline Commercial name & Radiopharmaceuticals & $\operatorname{RCP}(t=0)(n=3)$ & $\operatorname{RCPex}(n=3)$ & RCP requirements \\
\hline Neurolite & ${ }^{99 \mathrm{~m}} \mathrm{Tc}-\mathrm{ECD}$ & $98.38 \pm 0.54$ & $98.74 \pm 0.25$ & $\geq 90 \%$ \\
\hline Cardiolite & ${ }^{99 \mathrm{~m}}$ Tc-Sestamibi & $97.68 \pm 0.56$ & $97.77 \pm 0.88$ & $\geq 94 \%$ \\
\hline Stamicis & ${ }^{99 \mathrm{~m}}$ Tc-Sestamibi & $98.42 \pm 1.02$ & $99.03 \pm 0.48$ & $\geq 94 \%$ \\
\hline Technemibi & ${ }^{99 \mathrm{~m}}$ Tc-Sestamibi & $97.99 \pm 0.11$ & $98.15 \pm 0.14$ & $\geq 94 \%$ \\
\hline TechneScan & ${ }^{99 \mathrm{~m}} \mathrm{Tc}-\mathrm{MAG} 3$ & $98.11 \pm 0.62$ & $98.43 \pm 0.29$ & $\geq 95 \%$ \\
\hline Pentacis & ${ }^{99 \mathrm{~m}}$ Tc-DTPA & $99.16 \pm 0.32$ & $99.19 \pm 0.11$ & $\geq 95 \%$ \\
\hline Medronato II & ${ }^{99 \mathrm{~m}}$ Tc-MDP & $99.13 \pm 0.04$ & $98.77 \pm 0.08$ & $\geq 95 \%$ \\
\hline Osteocis & ${ }^{99 \mathrm{~m}} \mathrm{Tc}-\mathrm{HMDP}$ & $99.17 \pm 0.12$ & $98.76 \pm 0.29$ & $\geq 95 \%$ \\
\hline Nanocoll $(P R C=40 \mathrm{~min})$ & ${ }^{99 \mathrm{~m}} \mathrm{Tc}$-nanocolloids & $98.79 \pm 0.16$ & $98.92 \pm 0.59$ & $\geq 95 \%$ \\
\hline Renocis & ${ }^{99 \mathrm{~m}}$ Tc-DMSA & $99.11 \pm 0.35$ & $99.01 \pm 0.32$ & $\geq 95 \%$ \\
\hline
\end{tabular}

RCPex indicates the radiochemical purity at the end of the expired time.

TABLE 7: Evaluation of total technetium amount in ${ }^{99 \mathrm{~m}}$ Tc eluates coming from a generator with ${ }^{99}$ Mo calibrated activity of $10 \mathrm{GBq}$, at different times by previous elution.

\begin{tabular}{|c|c|c|c|c|}
\hline $\begin{array}{l}\text { Time by the } \\
\text { previous elution }\end{array}$ & $\begin{array}{c}\text { Amount of total } \\
\text { Tc calculated }\end{array}$ & $\begin{array}{c}{ }^{99 \mathrm{~g}} \mathrm{Tc} /{ }^{99 \mathrm{~m}} \mathrm{Tc} \text { ratio } \\
\text { calculated }\end{array}$ & $\begin{array}{l}\text { Amount of total } \\
\text { Tc found }\end{array}$ & $\begin{array}{c}{ }^{{ }^{99 \mathrm{~g}} \mathrm{Tc} /{ }^{99 \mathrm{~m}} \mathrm{Tc} \text { ratio }} \\
\text { found }\end{array}$ \\
\hline $72 \mathrm{~h}$ & $0.30 \mu \mathrm{g}$ & 11.84 & & \\
\hline $48 \mathrm{~h}$ & $0.22 \mu \mathrm{g}$ & 6.50 & $0.22 \pm 0.01$ & $6.68 \pm 0.31$ \\
\hline $36 \mathrm{~h}$ & $0.18 \mu \mathrm{g}$ & 4.34 & & \\
\hline $24 \mathrm{~h}$ & $0.13 \mu \mathrm{g}$ & 2.54 & $0.12 \pm 0.01$ & $3.23 \pm 0.15$ \\
\hline
\end{tabular}




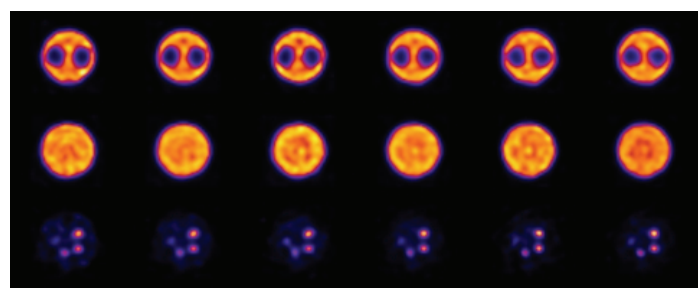

(a)

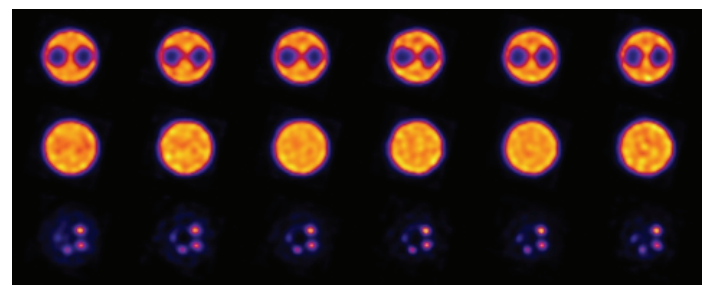

(b)

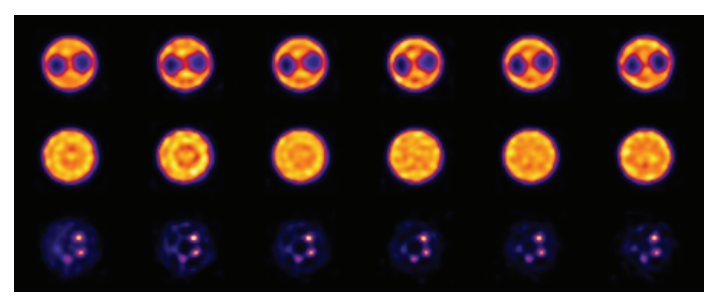

(c)

FIGURE 2: Reconstructed SPECT trans-axial slices of NEMA NU 42008 filled with ${ }^{99 \mathrm{~m}}$ Tc-pertechnetate solution. Top images (a) have $R=4.16$, middle images (b) have $R=9.51$, and bottom images (c) have $R=15.2$.

the experimental value of first eluates at 48 hours is in good agreement with thetheoretical value of 6.5 , the experimental value of eluates at 24 hours shows a large difference with respect to the theoretical value of 2.55 . This discrepancy could be explained by taking into account the elution efficiency $\varepsilon=0.91$ of ${ }^{99}$ Mo generators used in our work. Indeed, the recalculated ratio $R$ at 24 hours is included in the range (2.783.38) and depends on temporal sequence of previous elutions. The reconstructed SPECT images of NEMA phantom, for the different ${ }^{99 \mathrm{~g}} \mathrm{Tc} /{ }^{99 \mathrm{~m}} \mathrm{Tc}$ ratios $R$ used, are shown in Figure 2. The average reconstructed activity along the phantom axis, for the three values of $R$, is shown in Figure 3. The visual inspection on the images doesn't show significant difference in image quality and radioactivity distribution. Currently, CERETEC is the only commercial product for which the use of a fresh eluate, obtained from a generator eluted for not more than 24 hours, is required. This exception is linked to the low amount of tin chloride dehydrate in its formulation $(7.6 \mu \mathrm{g})$, which makes its radiochemical purity strongly influenced by the amount of ${ }^{99 \mathrm{~g}} \mathrm{Tc}$ present in the eluate. All formulations studied possess significantly higher amount of tin. A further limitation to the use of eluates characterized by greater amount of ${ }^{99 \mathrm{~g}} \mathrm{Tc}$ (elution intervals $>24 \mathrm{~h}$ ) could be due to radioprotection reasons related to the physical characteristics of ${ }^{99 \mathrm{~g}} \mathrm{Tc}\left(t_{1 / 2}=2 \times 10^{5} \mathrm{y}, \beta_{\max }=292 \mathrm{keV}\right)$. However

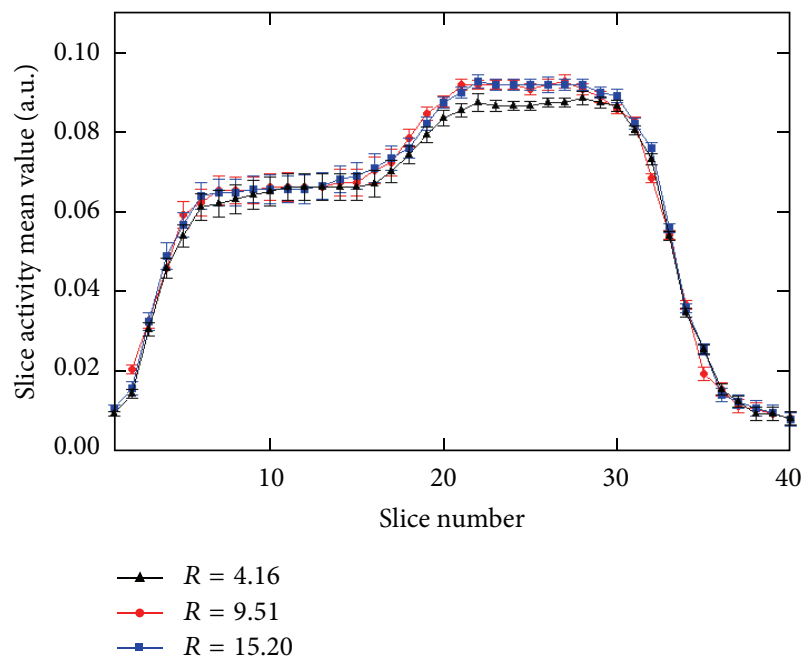

FIGURE 3: The average activity for reconstructed 40 slices of NEMA NU 4-2008 phantom filled with ${ }^{99 \mathrm{~m}} \mathrm{Tc}$-pertechnetate solution having $R=4.16, R=9.51$, and $R=15.2$.

the amount of radioactivity associated with the mass value is very low (e.g., $1 \mu \mathrm{g}$ of ${ }^{99 \mathrm{~g}} \mathrm{Tc}$ corresponds to $630 \mathrm{~Bq}$ ).

\section{Conclusion}

In order to first check the possible impact of different ${ }^{99 \mathrm{~g}} \mathrm{Tc} /{ }^{99 \mathrm{~m}} \mathrm{Tc}$ isomeric ratios on the preparation of different Tc-labeled pharmaceutical kits, the radiochemical purity and stability of ${ }^{99 \mathrm{~m}}$ Tc-Sestamibi, ${ }^{99 \mathrm{~m}} \mathrm{Tc}-\mathrm{ECD},{ }^{99 \mathrm{~m}} \mathrm{Tc}$ MAG3, ${ }^{99 m}$ Tc-DTPA, ${ }^{99 m}$ Tc-MDP, ${ }^{99 m}$ Tc-HMDP, ${ }^{99 m}$ Tcnanocolloids, and ${ }^{99 \mathrm{~m}} \mathrm{Tc}$-DMSA were studied by using ${ }^{99 \mathrm{~m}} \mathrm{Tc}$ eluates coming from ${ }^{99} \mathrm{Mo} /{ }^{99 \mathrm{~m}} \mathrm{Tc}$ generator eluted at different times from the previous elution. The results prove that radiochemical purity and stability of these radiopharmaceuticals are not affected up to ${ }^{99 \mathrm{~g}} \mathrm{Tc} /{ }^{99 \mathrm{~m}} \mathrm{Tc}$ ratio of 11.84 .

A future goal will be to repeat the experiments with ${ }^{99 \mathrm{~m}}$ Tc eluates coming from generators with ${ }^{99}$ Mo calibrated activity higher than $10 \mathrm{GBq}$, in order to check the possible impact of ${ }^{99 \mathrm{~g}} \mathrm{Tc}$ in higher ${ }^{99 \mathrm{~m}} \mathrm{Tc}$ activities solutions at different ${ }^{99 \mathrm{~g}} \mathrm{Tc} /{ }^{99 \mathrm{~m}} \mathrm{Tc}$ ratio.

Another future goal will be to study the impact of accelerated-based ${ }^{99 \mathrm{~g}} \mathrm{Tc}$ and other Tc-isotopes on the image quality and determine the allowed limit for ${ }^{99 \mathrm{~g}} \mathrm{Tc}$ and other Tc-isotopes in the final accelerator-produced Tc.

\section{Conflict of Interests}

The authors declare that they have no conflict of interests.

\section{Acknowledgments}

The authors would like to thank to Dr. L. M. Feggi (Unit of Nuclear Medicine, Sant' Anna Hospital, Ferrara) for equipment and IBA-CIS Bio International, GIF SUR YVETTE, Cedex France for generators. 


\section{References}

[1] S. Banerjee, M. R. Ambikalmajan Pillai, and N. Ramamoorthy, "Evolution of Tc-99m in diagnostic radiopharmaceuticals," Seminars in Nuclear Medicine, vol. 31, no. 4, pp. 260-277, 2001.

[2] O. P. D. Noronha, A. B. Sewatkar, and R. D. Ganatra, "Fission produced ${ }^{99} \mathrm{Mo}-{ }^{99 \mathrm{~m}} \mathrm{Tc}$ generator system for medical use," Journal of Nuclear Biology and Medicine, vol. 20, no. 1, pp. 32-36, 1976.

[3] N. Vinberg and K. Kristensen, "Fission Mo-99/Tc-99m generators-a study of their performance and quality," European Journal of Nuclear Medicine, vol. 5, no. 5, pp. 435-438, 1980.

[4] J. Vucina, "Technetium-99m production for use in nuclear medicine," Medicinski Pregled, vol. 53, no. 11-12, pp. 631-634, 2000.

[5] N. Knight, "Return of the radionuclide shortage," Journal of Nuclear Medicine, vol. 50, no. 7, pp. 13N-14N, 2009.

[6] J. Esposito, "Feasibility study report on alternative ${ }^{99} \mathrm{Mo} /{ }^{99 \mathrm{~m}} \mathrm{Tc}$ production routes using particle accelerators at LNL, (2001 version)," INFN-LNL-235, 2011.

[7] Report on the 1st Research Coordination Meeting of IAEA CRP Activities (code F22062), "Accelerator-based Alternatives to Non-HEU Production of ${ }^{99} \mathrm{Mo} /{ }^{99 \mathrm{~m}} \mathrm{Tc}$," Vancouver, Canada, April 2012.

[8] J. L. Vucina, "Radionuclide purity of ${ }^{99 \mathrm{~m}} \mathrm{Tc}$ eluate for use in nuclear medicine," Medicinski Pregled, vol. 49, no. 1-2, pp. 4144, 1996.

[9] D. M. Hill, R. K. Barnes, H. K. Y. Wong, and A. W. Zawadzki, "The quantification of technetium in generator-derived pertechnetate using ICP-MS," Applied Radiation and Isotopes, vol. 53, no. 3, pp. 415-419, 2000.

[10] J. Bonnyman, "Effect of milking efficiency on ${ }^{99} \mathrm{Tc}$ content of ${ }^{99 \mathrm{~m}}$ Tc derived from ${ }^{99 \mathrm{~m}}$ Tc generators," International Journal of Applied Radiation and Isotopes, vol. 34, no. 6, pp. 901-906, 1983.

[11] M. Marengo, C. Aprile, C. Bagnara et al., "Quality control of ${ }^{99} \mathrm{Mo} /{ }^{99 \mathrm{~m}} \mathrm{Tc}$ generators: results of a survey of the radiopharmacy working group of the Italian Association of Nuclear Medicine (AIMN)," Nuclear Medicine Communications, vol. 20, no. 11, pp. 1077-1084, 1999.

[12] M. M. Webber, M. D. Cragin, and W. K. Victery, "Aluminum content in eluents from commercial technetium generators," Journal of Nuclear Medicine, vol. 12, no. 10, p. 700, 1971.

[13] A. M. Zimmer and D. G. Pavel, "Rapid miniaturized chromatographic quality-control procedures for Tc-99m radiopharmaceuticals," Journal of Nuclear Medicine, vol. 18, no. 12, pp. 12301233, 1977.

[14] European Pharmacopoeia, 7th edition, Sodium pertechnetate $\left({ }^{99 \mathrm{~m}} \mathrm{Tc}\right.$ ) injection (fission) (0124).

[15] A. Hammermaier, E. Reich, and W. Bogl, "Chemical, radiochemical, and radionuclide purity of eluates from different commercial fission ${ }^{99} \mathrm{Mo} /{ }^{99 \mathrm{~m}} \mathrm{Tc}$ generators," European Journal of Nuclear Medicine, vol. 12, no. 1, pp. 41-46, 1986.

[16] P. Nasman and T. Vayrynen, "Impurities of ${ }^{99 \mathrm{~m}}$ Tc-generators," European Journal of Nuclear Medicine, vol. 8, no. 1, pp. 26-29, 1983.

[17] T. Vayrynen, P. Nasman, and K. Kiviniitty, "Residual activity of Tc-generators," European Journal of Nuclear Medicine, vol. 6, no. 6, pp. 269-271, 1981.

[18] S. Hoory, D. Bandyopadhyay, J.-C. Vaugeois, and L. M. Levy, "Impurities in generator eluates and radiopharmaceuticals: a computerized quality assurance approach," Health Physics, vol. 50, no. 6, pp. 843-848, 1986.
[19] "Radiopharmacy and quality control pharmacists subcommittees of the regional pharmaceutical officers commitee. Quality assurance of radiopharmaceuticals," Nuclear Medicine Communication, vol. 15, pp. 886-889, 1994.

[20] E. M. Podolak Jr., " ${ }^{1134} \mathrm{Cs},{ }^{86} \mathrm{Rb}$, and ${ }^{60} \mathrm{Co}$ in ${ }^{99} \mathrm{Mo}-{ }^{99 \mathrm{~m}} \mathrm{Tc}$ generator eluate," Journal of Nuclear Medicine, vol. 13, no. 6, pp. 388390, 1972.

[21] I. Zolle, Technetium-99m Pharmaceuticals: Preparation and Quality Control in Nuclear Medicine, Springer, Berlin, Germany, 2007.

[22] A. Del Guerra, A. Bartoli, N. Belcari et al., "Performance evaluation of the fully engineered YAP-(S)PET scanner for small animal imaging," IEEE Transactions on Nuclear Science, vol. 53, no. 3, pp. 1078-1083, 2006. 


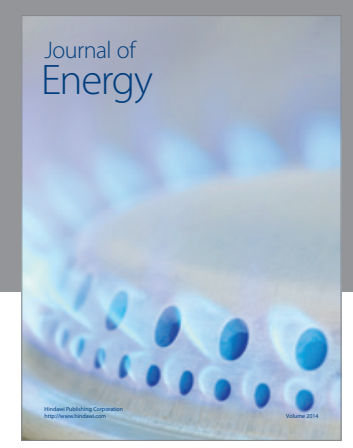

Journal of

Industrial Engineering
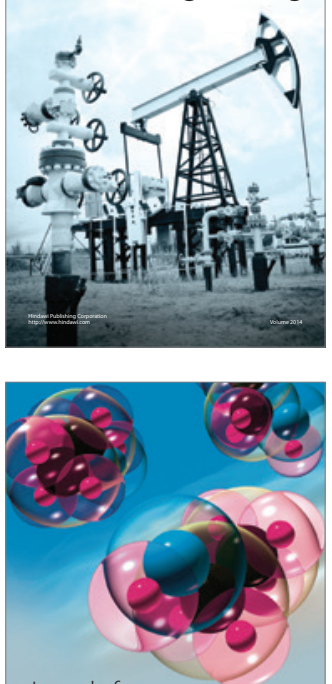

Fuels
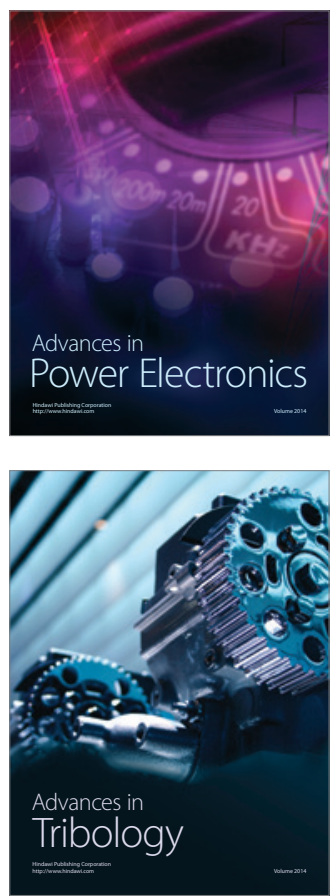

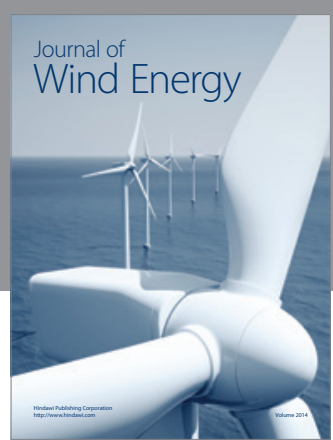

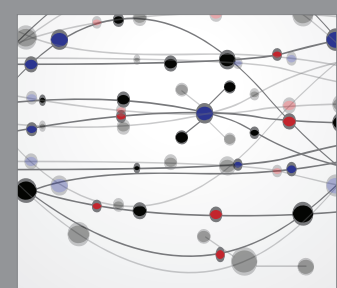

The Scientific World Journal

Submit your manuscripts at http://www.hindawi.com

Journal of

Structures
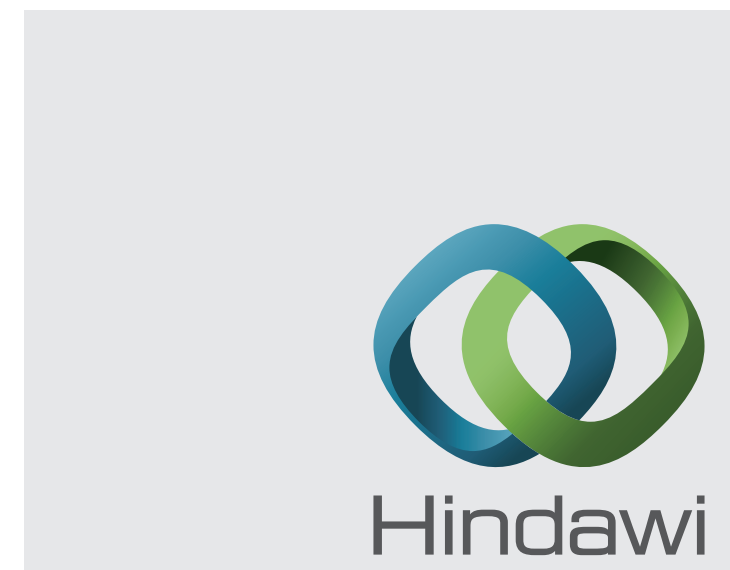

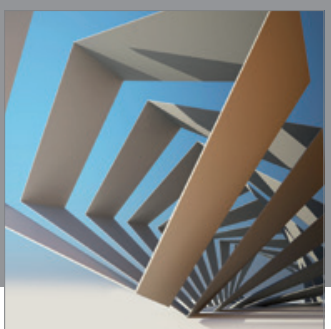

Rotating

Machinery
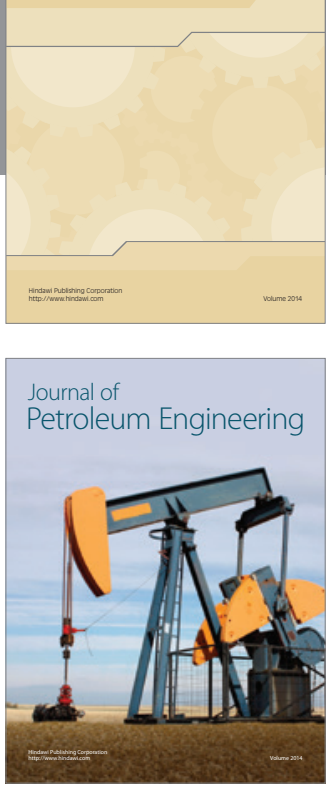

Journal of

Solar Energy
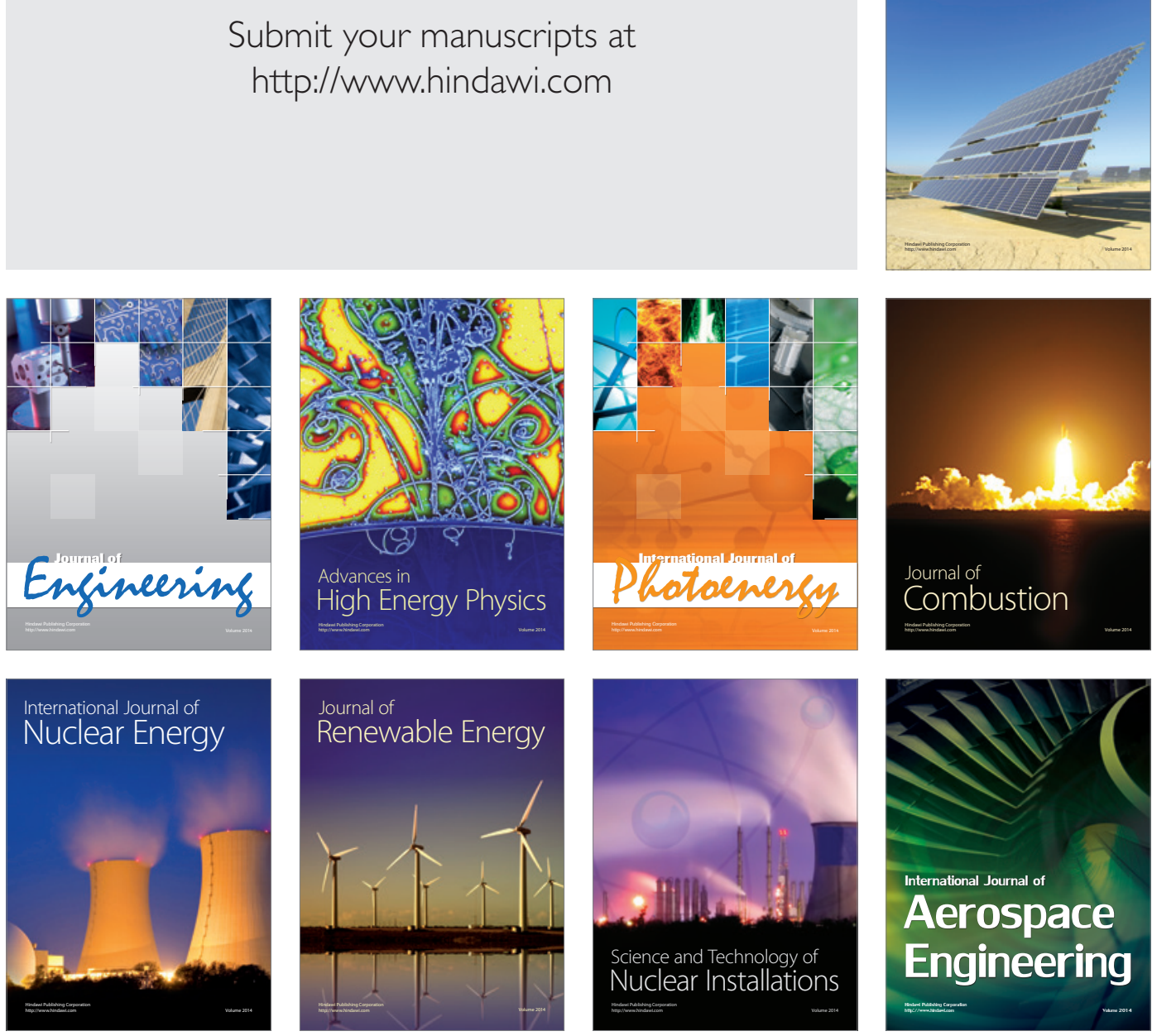